\title{
Why I . . . take a lunch break
}

\section{Geoffrey Lester, associate clinical lecturer and basic physician trainee in Sydney, Australia, tells Francesca Robinson why he always takes a lunch break}

\section{Francesca Robinson}

Hampshire, UK

"It's important for me to make time to eat and have a break, irrespective of what's going on in my working day," Lester says. "I can't function in the afternoon if I don't have a full belly and some coffee at lunchtime."

This is a concept that was drummed into him as a child. "My dad always drilled into us the importance of sitting down and having a good lunch with time to allow it to digest," he explains. Aged 34, Lester is more conscious than most people of the importance of a healthy lifestyle, having nearly died three times as the result of a ruptured aorta. He has non-syndromic thoracic aortic aneurysm and dissection syndrome (ns-TAADS), a condition which makes him value each day.

Lester started his working life in finance but after his brush with death he switched to medicine and developed a special interest in cardiology. His view is that doctors need to look after themselves. "Without healthy doctors you can't have healthy patients and being healthy for me involves having three meals a day," he says.

He says there is an abundance of evidence showing that doctors who are hungry or thirsty don't perform well, including a study showing that time pressed junior doctors can be more dehydrated than the patients they care for. ${ }^{1}$

Lester succeeds in taking a lunch break every day because he lets people know that it's non-negotiable. Having worked outside the health sector and being older than the average trainee he has the confidence to tell colleagues he's going for a lunch break and that whatever they need him for can wait unless the patient is sick or acutely unwell.

Lester says he will take as long as it takes to get lunch and eat it, plus or minus 10 minutes either side, which usually comes to 30 minutes or even an hour on a good day. He will eat a healthy meal that is not overloaded with carbohydrates to avoid any afternoon sleepiness. If he is working a night shift, he will take the same length of break.

During his break he may do some "life admin" or chat to colleagues. "Socialising is part of taking a lunch break," Lester says. "Medicine is a taxing job, so this is a chance to have a social debrief with colleagues about a difficult patient or a personal matter. This opportunity to open up and talk about your feelings can be as important a part of the break as eating and is something you might otherwise not have time for during the day."

Lester also encourages his juniors to have lunch with him as this is a chance to bond and chat about problems in a non-work environment.

Recently, the idea of a protected lunch break has been adopted as part of a doctors' wellbeing programme by the Royal Prince Alfred Hospital in Sydney where Lester works. ${ }^{2}$ From noon to $1 \mathrm{pm}$ non-urgent calls are banned and a paged message goes out saying that doctors are on their lunch break and any non-urgent contacts must be withheld during the hour. This policy could be adopted by any hospital or GP practice, says Lester.

"In the past, the lunch break was an afterthought for doctors and was treated as a reward rather than something we need in order to function," he says. "But this is about protecting the medical workforce and it's not something that is hard to do."

How to ring fence a lunch break

- Create awareness among your colleagues that eating lunch is a vita part of the day

- Explain that not only will you perform better but patient outcomes will also improve

- Make a noise about it: announce in a reasonably loud voice that you are going for your lunch

- Let people know when you will be back but that if there is an emergency they can page you

- Take a break as a team: this communicates to the rest of the department that this is an important team exercise

Solomon AW, Kirwan CJ, Alexander NDE, et alProspective Analysis of Renal Compensation for Hypohydration in Exhausted Doctors (PARCHED) Investigators. Urine output on an intensive care unit: case-control study. BMJ 2010;341:c6761. 10.1136/bmj.c6761 21156738

2 Sydney Local Health District. MDOK healthy minds healthy medicine. www.slhd.nsw.gov. au/rpa/bptn/BPT.html.

Published by the BMJ Publishing Group Limited. For permission to use (where not already granted under a licence) please go to http://group.bmj.com/group/rights-licensing/ permissions 